\title{
Determining the effects of films with suicidal content: a laboratory experiment
}

\author{
Benedikt Till, Markus Strauss, Gernot Sonneck and Thomas Niederkrotenthaler
}

\section{Background}

Media stories on suicide can increase suicidal ideation, but little is known about variations in media effects with regard to audience vulnerability and story contents.

\section{Aims}

We investigated the impact of three drama films with suicida content that varied with regard to the final outcome (suicide completion, mastery of crisis and death by natural causes) and tested the moderating effect of baseline suicidality of the participants on the effects.

\section{Method}

Within a laboratory setting, we randomly assigned 95 adults to three film groups. We used questionnaires to analyse the effects of the films on mood, depression, life satisfaction, self-worth, assumed benevolence of the world and suicidality, as well as identification with the protagonist. We stratified the sample into participants with suicidal tendencies above and below the sample median.

\section{Results}

The film that ended with the protagonist's suicide led to a deterioration of mood particularly in individuals with baseline suicidality below the median, who also experienced an increase in self-worth. Participants with stronger suicida tendencies experienced a rise in suicidality that depended on their level of identification with the protagonist. The film featuring the main character positively coping with his crisis increased life satisfaction particularly among participants with higher suicidal tendencies.

\section{Conclusions}

The effects of suicide-related media material seem to vary with individual vulnerability and with type of media portrayal Individuals with lower vulnerability experience more emotional reactions when exposed to a film culminating in suicide, but individuals with higher vulnerability experience a rise in suicidal tendencies particularly if they identify with the protagonist who died by suicide. In contrast, portrayals of individual mastery of crisis may have beneficial effects in more vulnerable individuals.

\section{Declaration of interest}

None.

\section{Copyright and usage}

(c) The Royal College of Psychiatrists 2015.
Over the past few decades, a considerable body of literature has focused on the question of whether media portrayals of suicide result in additional suicides, the so-called copycat effect. ${ }^{1,2}$ The risk of copycat effect has been reported to be strongest for sensationalist reports of celebrity suicides. ${ }^{3}$ With regard to fictional suicide stories portrayed in films, the evidence is more inconclusive, but some studies have reported increases in suicides following exposure to fictional stories, ${ }^{4,5}$ especially when the suicide method portrayed in a film was matched with the suicide rate by that particular method in the population. ${ }^{6}$ Some studies have suggested that identification with the protagonist of a media story may be a component in the pathway to copycat behaviour of violent media stimuli in general ${ }^{7}$ and suicide portrayals in particular. ${ }^{8,9}$ Ecological studies are frequently used in this research area, but these studies have many limitations. Most importantly, it is not possible to determine whether individuals who took their own life following a suicide portrayal in the media were actually exposed to the story. ${ }^{5}$

Laboratory experiments provide an alternative to overcome this limitation, but have rarely been used to test the effects of portrayals of suicide on audiences. In a recent laboratory experiment, ${ }^{10}$ personal suicidal ideation had a significant impact on how people coped with the film's content; specifically, the higher viewers scored for suicidal ideation, the more they tended to use films about suicide to develop ideas on how to go through life and address their own problems. This finding is consistent with previous research, which indicates that individuals with a history of suicide attempts or suicidal ideation are particularly vulnerable to engaging in suicidal behaviour following exposure to a suicide story in the media, ${ }^{11,12}$ and are more likely to report exposure to movies culminating in the protagonist's suicide. ${ }^{13}$
The effects of media portrayals may also vary with the manner in which suicidal ideation is portrayed. Niederkrotenthaler et al ${ }^{14}$ found an association between sensationalist suicide reports and increases in suicide rates, but stories on individuals who contemplated suicide but then coped with adverse circumstances in a constructive manner were associated with a short-term decrease in suicide rates. This finding suggests that some media stories with suicidal content may even have a protective effect, called the Papageno effect. ${ }^{14}$ With more time spent in Western societies watching films than performing any other leisure activity, ${ }^{4,15}$ and an increasing focus in mental health promotion on suicide awareness campaigns via the media, ${ }^{16,17}$ further research is needed to investigate differences in the effects of films with regard to the outcomes of portrayed suicidal crises and the level of suicidal ideation of the audience. In the present study, we conducted a laboratory experiment to analyse the effects of three movies with different crisis outcomes on mood, depression, life satisfaction, self-worth, assumed benevolence of the world and suicidality. We also analysed how viewers identified with the protagonist of the respective film and assessed the impact of personal suicidal ideation on the observed film effects.

\section{Method}

\section{Participants}

The participants in this study were 95 individuals living in Austria ( 65 women and 30 men). They were recruited by means of posters, flyers and public announcements at facilities of the University of Vienna and the Medical University of Vienna and at other public venues (e.g. the Civic Centre) in Vienna, Austria, between January 
and April 2012. The participants' mean age was 27.32 years (s.d. =10.43). High school graduation was the average level of education for both men and women. Women between 20 and 30 years of age and with high school and college degrees were over-represented in our sample compared with the total population in Austria.

\section{Materials and procedure}

We conducted a laboratory experiment with three groups of participants who watched a film featuring the portrayal of a suicidal crisis, each with a different outcome/ending. The films we selected were similar in terms of genre (i.e. drama) and all were Hollywood productions. Because research shows that film effects are influenced by the amount of aggression and violence shown, ${ }^{7}$ we made sure to select only films that contained little or no on-screen violence as defined by Huesmann and Taylor. ${ }^{7}$

Group 1 viewed the film 'Night, Mother (USA, 1986), an American drama that ends with the protagonist, Jessie, taking her own life. Jessie is a middle-aged woman with epilepsy who is unable to keep a job or drive. Her marriage has failed and her drug-addicted son has run away from home. One night, she calmly tells her widowed mother, with whom she lives, that she plans to end her life that very evening. Despite her mother's attempts to convince her that life is worth living, which are the main focus of the film but never result in any relief, the film ends with Jessie locking herself in her room and fatally shooting herself, off-screen. Regarding the amount of violence and aggression shown, this film contains several instances of non-physical aggression (e.g. insults, intimidation) and one case of mild physical aggression (i.e. shoving), as well as several instances of mild self-directed aggression by the protagonist.

Group 2 viewed the movie A Single Man (USA, 2009), an American drama that ends with the protagonist suffering a heart attack and dying. The protagonist, George, is a middle-aged English college professor who is unable to cope with his loss one year after the sudden death of his long-term partner. As he prepares to take his own life, he comes into contact with a student, Kenny, who shows interest in him. They fall in love and George overcomes his suicidal crisis. Shortly after, however, George dies of a heart attack. There is no violence or aggression in this film.

Group 3 watched the film Elizabethtown (USA, 2005), an American romantic comedy-drama that has a happy ending. Drew Baylor is the designer of the Späsmotica shoe, a hyped but flawed new product which, his boss informs him, will lose nearly a billion dollars to his company. Drew is fired for the mistake and is subsequently left by his girlfriend. Drew then plans an elaborate suicide. However, at the exact moment of his act of despair, his sister calls him to tell him that his father has just died and asks him to travel to Elizabethtown to retrieve his body for cremation. During his flight, he meets Claire, who changes his perspective on life. The film concludes with Drew falling in love with Claire and overcoming his crisis. No violence or aggression are portrayed in this film.

Participation in the study was voluntary and anonymous, and the participants were randomly allocated to the groups (i.e. 31 participants were assigned to groups 1 and 2, respectively, and 33 participants were assigned to group 3). Questionnaires on mood, depression, life satisfaction, self-worth, assumed benevolence of the world and suicidality were completed before and immediately after the film. Identification with the protagonist was also measured after the film using a questionnaire.

For ethical reasons, only participants with suicidality and depression levels below established cut-off scores for the respective questionnaires were included. Four individuals were excluded from the study owing to suicidality or depression scores above the respective cut-off score. One individual decided to end participation in this study prematurely. The selection procedure reduced the original sample of 100 to 95 participants $(n=95)$. All participants were offered psychological counselling to help them cope with any distress resulting from exposure to the film or from answering questions on suicidality. The study took place at the Medical University of Vienna, Austria, and was approved by the Ethics Committee of the Medical University of Vienna and the Vienna General Hospital (study protocol 942/2011).

\section{Measures}

Mood subscale of the Affective State Scale

The mood subscale of the Affective State Scale ${ }^{18}$ uses responses to eight adjectives, such as merry or sad, scored on a scale from 1 (not at all) to 4 (highly), to provide scores on the participants' current mood $(\alpha=0.86)$. We defined mood as a group of persistent feelings associated with evaluative and cognitive states that influence all future evaluations, feelings and actions. ${ }^{19}$

\section{Erlanger Depression Scale}

The Erlanger Depression Scale ${ }^{20}$ uses eight self-report items (e.g. 'I want to cry') to assess symptoms of depression. Items are rated on a scale from 0 (completely wrong) to 4 (exactly right). Cronbach's alpha for this score was 0.66. Individuals with depression scores $\geqslant 17$ were considered depressed and were excluded from the study.

\section{Satisfaction with Life Scale}

The Satisfaction with Life Scale ${ }^{21}$ is a five-item self-report measure used to assess life satisfaction (e.g. 'I am satisfied with my life'). Items are rated on a scale of 1 (strongly disagree) to 7 (strongly agree). Cronbach's alpha for this score was 0.84 .

\section{Self-worth subscale of World Assumptions Scale}

The self-worth subscale of the World Assumptions Scale ${ }^{22}$ is a four-item self-report measure that generates a score for the participant's self-worth (e.g. 'I am very satisfied with the kind of person I am'). Items are rated on a scale of 1 (disagree completely) to 6 (agree completely). Cronbach's alpha for this score was 0.72 .

\section{Reasons for Living Scale}

The Reasons for Living Scale ${ }^{23}$ is a 48 -item self-report measure that assesses beliefs and expectations about not committing suicide. It explores the (positive) adaptive reasons to refrain from suicide and the positive ways in which people address suicidal thoughts and feelings. Unlike other measures of suicidality, this scale has a solid theoretical base and, by focusing on strengths rather than weaknesses, assesses suicidality without the risk of inducing a depressive mood, ${ }^{24}$ which has occasionally occurred with other scales. ${ }^{25}$ Items (e.g. "I am afraid of the actual "act" of killing myself') are rated on a scale of 1 (not at all important) to 6 (extremely important). The measures were transformed so that high scores indicated a higher manifestation of suicidal ideation $(\alpha=0.83)$. Individuals with a suicidality score $\geqslant 106$ were considered to be suicidal and excluded from the study.

\section{Benevolence of the world subscale of the World Assumptions Scale}

The benevolence of the world subscale of the World Assumptions $\mathrm{Scale}^{22}$ is a four-item self-report measure that generates a score for participants' assumed benevolence of the world (e.g. 'There is 
more good than evil in the world'). Items are rated on a scale of 1 (disagree completely) to 6 (agree completely). Cronbach's alpha for this score was 0.79 .

\section{Cohen's Identification Scale}

Cohen's Identification Scale ${ }^{26}$ is a 10 -items scale that measures an individual's identification with a specific character in a TV show or film (e.g. 'While viewing the film I could feel the emotions character X portrayed') answered on a five-point measure from 1 (disagree) to 5 (agree). Cronbach's alpha for this score was 0.91 .

\section{Data analysis}

When computing the parameters, negative item scores were reversed. The items were then added to sum scores. Table 1 presents an overview of each parameter's mean and standard deviation before and after the movie screening. High scores indicate a high manifestation of the variable. For mood, high scores indicate a good mood. The scores of each dependent measure were subjected to a film group ('Night, Mother, A Single Man, Elizabethtown) test condition (pre-film, post-film) analysis of variance (ANOVA) using the F-test. Film group was a between-subjects factor, and test condition was a within-subjects factor in this analysis. Additionally, paired $t$-tests were performed to analyse the film-induced changes in the dependent measures in each film group.

To differentiate the effects on participants with lower $v$. higher suicidal tendencies, we split our sample into two groups by the median of the suicidality scores collected before the film (i.e. at baseline). Differences in identification with the protagonist of the respective film were assessed using an ANOVA with identification as the dependent variable and film groups as the factor. Associations between identification and baseline suicidality were estimated with Pearson product-moment correlations for each film group. Regression models with suicidality scores post-film screening as the dependent variable and baseline suicidality and identification as the independent variables were created and the interaction effects between baseline suicidality and identification were tested by introducing corresponding product terms into the models.

\section{Results}

There was no significant difference with regard to baseline suicidality (i.e. suicidality scores before the film screening) among the viewers of the three films $(F(2,95)=0.18, P=0.83)$. The distribution of the suicidality scores at baseline for each film group and for all groups combined is shown in Fig. 1.

\section{Main effects and interactions}

The analysis of the film effects revealed a significant film group $\times$ test condition interaction for $\operatorname{mood}(F(2,91)=14.16, P<0.001)$, depression $(F(2,92)=7.49, \quad P<0.01)$ and life satisfaction $(F(2,91)=7.17, P<0.01)$. With regard to assumed benevolence of the world, the ANOVA indicated a significant main effect $(F(1,94)=7.99, \quad P<0.01)$, but no significant interaction $(F(1,94)=0.67, P=0.51)$. Furthermore, there was no significant main effect $(F(1,94)=2.22, P=0.13)$ and no significant interaction $(F(2,94)=1.44, P=0.24)$ for self-worth. The main effect for suicidality was close to the boundary of statistical significance $(F(1,95)=2.73, \quad P=0.10)$ and there was no significant film group $\times$ test condition interaction $(F(2,95)=0.48, P=0.61)$.

\section{The impact of 'Night, Mother (film ending with the protagonist's suicide)}

Evaluation of the interaction means and analyses of changes in the individual groups via paired $t$-tests indicated that there was a significant deterioration of mood and an increase in depression in this film group (see Table 1). When our sample was stratified, according to the suicidality score collected before the film screening $(\mu=81)$, into one group with relatively lower suicidality $(n=49, \mu=55$, interquartile range $(\mathrm{IQR})=36, \min =1, \max =81)$ and one group with comparatively higher suicidality $(n=46$, $\mu=97, I Q R=13, \min =83, \max =105)$, there was a significant deterioration of mood and an increase in depression among participants with lower suicidality, but not among those with higher suicidality. The individuals with lower suicidality also experienced a change in self-perception in terms of an increase in self-worth. In contrast, there was a significant increase in suicidality among viewers with higher suicidality (see Table 2 and Fig. 2).

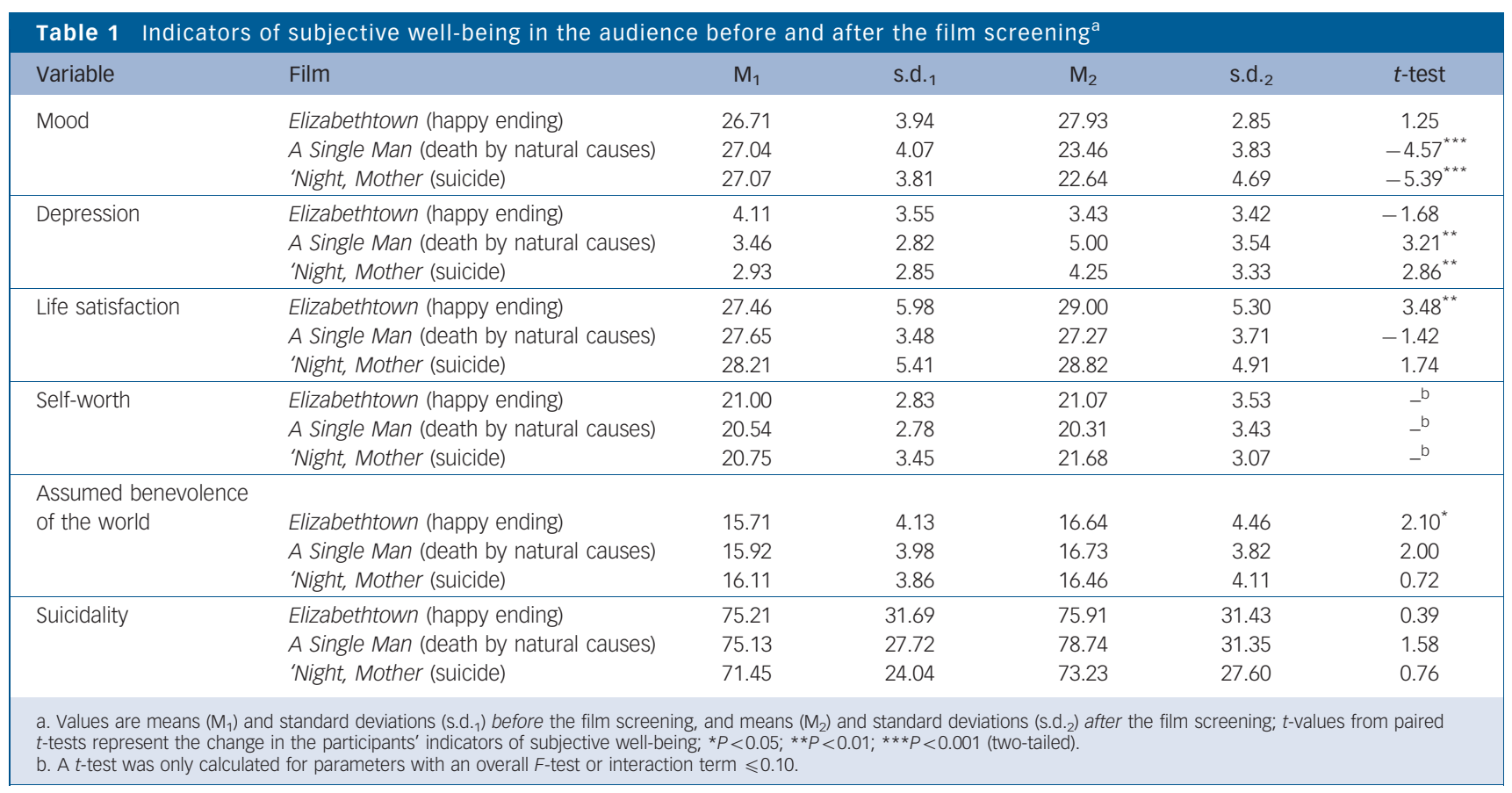




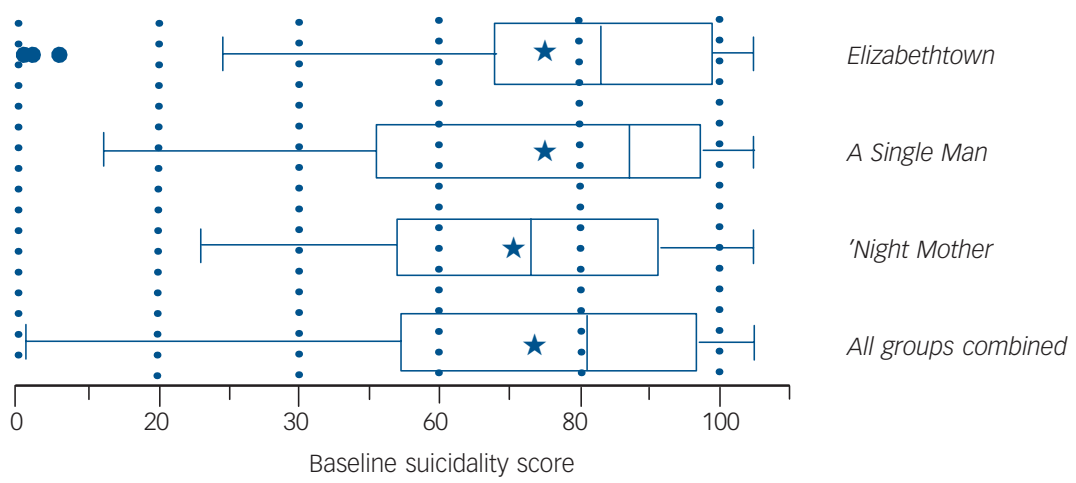

Fig. 1 Distribution of suicidality among viewers in the three film groups and among all viewers combined. Boxes represent values between the 25th and 75th percentiles; whiskers represent the upper and lower adjacent values; vertical lines represent the median; $\star$ represents the arithmetic mean; and $\bullet$ represents outliers.

\begin{tabular}{|c|c|c|c|c|c|c|c|c|c|c|c|}
\hline \multirow[b]{2}{*}{ Variable } & \multirow[b]{2}{*}{ Film } & \multicolumn{5}{|c|}{ Lower suicidality } & \multicolumn{5}{|c|}{ Higher suicidality } \\
\hline & & $M_{1}$ & s.d. ${ }_{1}$ & $\mathrm{M}_{2}$ & s.d.2 & $t$-test & $M_{1}$ & s.d. 1 & $\mathrm{M}_{2}$ & s.d. 2 & $t$-test \\
\hline \multirow[t]{3}{*}{ Mood } & ET & 28.33 & 2.66 & 28.00 & 2.51 & -0.45 & 25.56 & 4.29 & 27.28 & 3.41 & 1.74 \\
\hline & SM & 27.36 & 2.59 & 22.93 & 3.81 & $-5.88^{* * *}$ & 26.38 & 4.91 & 23.94 & 4.82 & -1.84 \\
\hline & NM & 27.40 & 3.36 & 21.40 & 3.98 & $-5.53^{* * *}$ & 26.64 & 4.20 & 24.64 & 4.80 & -2.00 \\
\hline \multirow[t]{3}{*}{ Depression } & ET & 2.80 & 2.57 & 2.40 & 2.06 & -0.84 & 5.78 & 4.56 & 4.22 & 3.90 & -1.49 \\
\hline & SM & 3.36 & 1.91 & 4.93 & 1.77 & $3.02^{*}$ & 3.71 & 3.27 & 5.00 & 4.65 & 1.91 \\
\hline & NM & 2.40 & 1.50 & 4.33 & 2.77 & $2.72^{*}$ & 3.27 & 4.32 & 3.82 & 4.22 & 1.07 \\
\hline \multirow[t]{3}{*}{ Life satisfaction } & ET & 30.00 & 3.87 & 31.36 & 2.90 & 2.14 & 25.44 & 6.04 & 26.44 & 5.94 & $2.70^{*}$ \\
\hline & SM & 28.00 & 3.19 & 27.64 & 3.25 & -0.75 & 25.82 & 5.45 & 25.38 & 6.19 & -1.21 \\
\hline & NM & 29.15 & 4.76 & 29.35 & 4.45 & 0.59 & 27.27 & 6.02 & 28.45 & 5.32 & 1.92 \\
\hline \multirow[t]{3}{*}{ Self-worth } & ET & 22.20 & 2.27 & 22.47 & 1.92 & 0.53 & 19.67 & 2.79 & 19.61 & 3.73 & -0.09 \\
\hline & SM & 20.57 & 2.47 & 20.14 & 2.98 & -0.68 & 19.94 & 3.86 & 20.44 & 3.85 & 0.69 \\
\hline & NM & 20.90 & 3.23 & 21.90 & 2.81 & $3.56^{* *}$ & 20.73 & 3.41 & 21.27 & 3.26 & 1.32 \\
\hline \multirow[t]{3}{*}{$\begin{array}{l}\text { Assumed benevolence } \\
\text { of the world }\end{array}$} & ET & 16.93 & 3.75 & 17.80 & 3.57 & 1.71 & 14.28 & 3.66 & 15.00 & 4.52 & 1.31 \\
\hline & SM & 16.29 & 4.16 & 16.79 & 3.53 & 1.24 & 14.53 & 3.89 & 15.63 & 4.26 & 1.59 \\
\hline & NM & 15.70 & 4.61 & 16.15 & 4.76 & 1.04 & 15.55 & 3.17 & 15.45 & 3.80 & -0.14 \\
\hline \multirow[t]{3}{*}{ Suicidality } & ET & 49.40 & 30.21 & 52.40 & 30.47 & 1.59 & 96.72 & 7.79 & 95.50 & 14.15 & -0.43 \\
\hline & SM & 49.00 & 19.29 & 51.71 & 21.23 & 1.11 & 96.65 & 7.03 & 101.0 & 17.64 & 1.18 \\
\hline & NM & 57.30 & 16.95 & 56.35 & 16.96 & -0.29 & 97.18 & 7.71 & 103.9 & 11.53 & $3.13^{*}$ \\
\hline
\end{tabular}

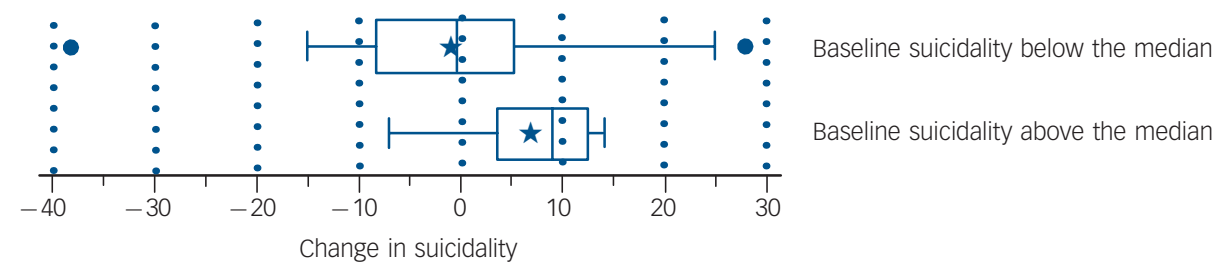

Fig. 2 Distribution of change in suicidality among viewers of 'Night, Mother with lower suicidality and higher suicidality. Boxes represent values between the 25th and 75th percentiles; whiskers represent the upper and lower adjacent values; vertical lines represent the median; $\star$ represents the arithmetic mean; and $\bullet$ represents outliers.

\section{The impact of $A$ Single Man (film ending with the protagonist's death by natural causes)}

There was a significant deterioration of mood, an increase in depression and an increase close to statistical significance in assumed benevolence of the world among viewers of $A$ Single Man. The stratified analyses revealed that the deterioration of mood and the increase in depression were significant among participants with lower suicidality, but not among those with higher suicidality (Table 2).

\section{The impact of Elizabethtown (film concluding with a happy ending)}

Participants in this film group had significantly increased scores for life satisfaction and benevolence of the world after the film. The increase of life satisfaction was significant among viewers with higher suicidality and close to statistical significance among those with lower suicidality. There was no significant effect in the analyses of benevolence of the world stratified for baseline suicidality (Table 2). 


\section{Identification with the protagonist}

Identification of study participants with the protagonist of 'Night, Mother, who takes her own life, was significantly lower than with the protagonist of A Single Man, who dies from natural causes (heart attack), or with the protagonist in Elizabethtown who overcomes his crisis $(F(2,95)=13.38, P<0.001)$. Identification with the protagonist of 'Night, Mother was significantly associated with baseline suicidality $(r=0.44, n=31, P<0.05)$. The more suicidal the viewers were before the film screening, the more they identified with the main character of 'Night, Mother. Identification and suicidality were not significantly associated among viewers of A Single Man $(r=-0.04, n=31, P=0.83)$ and Elizabethtown $(r=0.00, n=33, P=0.99)$.

For the film 'Night, Mother, there was a significant interaction effect between identification and baseline suicidality on suicidality after film screening $(B=0.04$, s.e. $=0.01, P<0.05)$ in the regression model $\left(F(3,31)=44.29, P<0.001\right.$, adjusted $\left.R^{2}=0.81\right)$. The interaction effect is shown in Fig. 3. There was no significant interaction term for the films $A$ Single Man $(B=-0.01$, s.e. $=0.01, P=0.59)$ and Elizabethtown $(B=0.00$, s.e. $=0.01, P=0.79)$.

\section{Discussion}

\section{The impact of 'Night, Mother (film ending with the protagonist's suicide)}

The results of the present study show that the viewers of this film, which ends with the suicide of the protagonist, were significantly sadder, unhappier and more depressed after the film screening than they were before the screening. The viewing of this movie led to a significant deterioration of viewers' mood and an increase in depression scores. This finding is generally concordant with affective disposition theory, which proposes that an outcome that victimises protagonists and portrays their downfall is deplored by viewers. ${ }^{27}$ Previous studies demonstrated a similar deterioration of mood after the screening of movies ending with the protagonist's suicide. ${ }^{28,29}$ The finding that a significant deterioration of mood and increase of depression scores was found only among viewers with lower suicidality but not among those with higher suicidality in the present study is consistent with the concept of affective constriction. Suicidality can be understood as a transient psychological constriction of perception, intellect and affect. ${ }^{30,31}$ The affective constriction found in suicidal individuals is reflected in a diminution or cessation of feeling. ${ }^{31}$ The resulting reduction in affective resonance and variability may prevent any change in the affective state of a suicidal individual when exposed to a film ending with the protagonist's suicide. ${ }^{30}$

While the deterioration in mood was only seen in participants with lower suicidal tendencies, those who recorded suicidal ideation scores above the median of the sample before the film screening experienced an increase in suicidal ideation after the film screening. This finding is consistent with the concept of perceptual constriction, ${ }^{30,31}$ which emphasises that suicidal individuals tend to be occupied with thoughts about suicide and death, and may not be able to distance themselves from the dramatic suicidal development portrayed in a movie that culminates in the protagonist's suicide.

Identification with the protagonist may play a relevant role in the increase in suicidality scores among vulnerable individuals. As indicated by the interaction effect between vulnerability as indicated by baseline suicidality and identification with the protagonist, it is those individuals who identify with the character portrayed who are particularly prone to increases in suicidal ideation. Individuals with comparatively higher suicidality who identify with the protagonist may find the protagonist of a suicidal film more appealing and more realistic ${ }^{7}$ and therefore more relevant to their own lives in comparison with individuals with lower suicidality or individuals who do not identify with the protagonist. Based on the finding that viewers of 'Night, Mother, who showed higher baseline suicidality and more strongly identified with the protagonist, formed the group who experienced the strongest increase of suicidality scores when exposed to the movie, extreme caution is then necessary when other suicidal individuals are exposed to suicide in the media, because those individuals who particularly identify with the suicidal protagonist may respond with stronger increases in suicidal ideation.

The differences in film effects with regard to viewers' baseline suicidality are further highlighted by the effect of 'Night, Mother on the viewers' self-worth, which increased in the group with

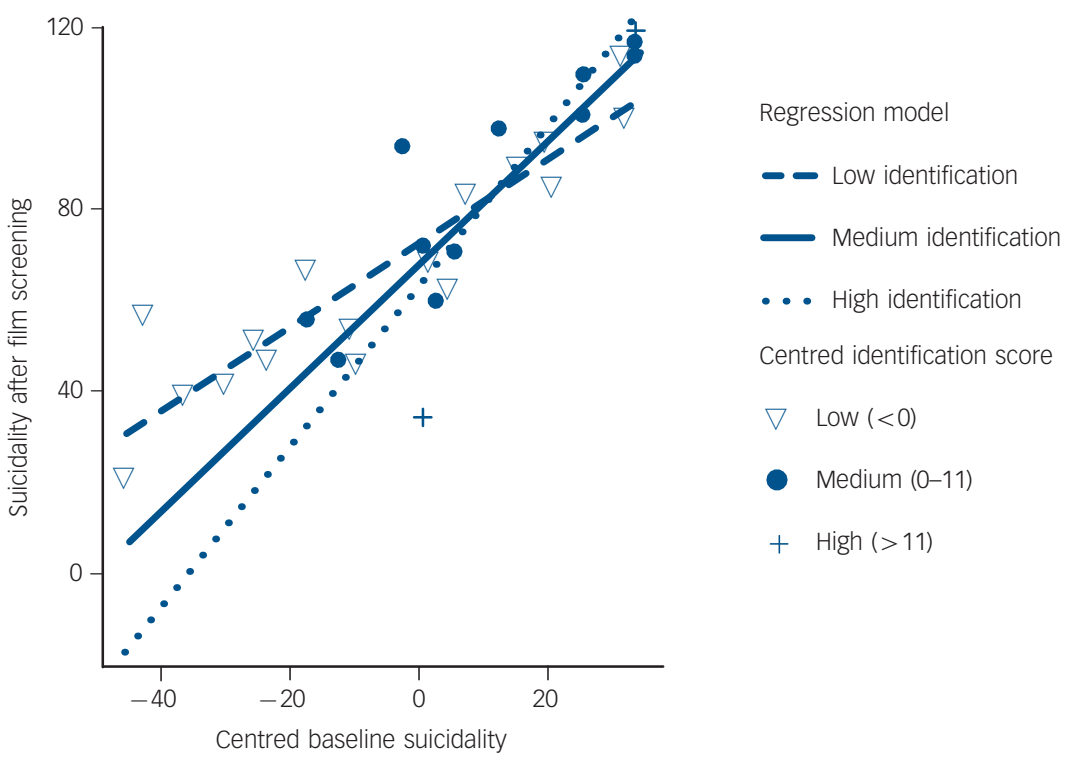

Fig. 3 Interaction effect between identification and baseline suicidality on post-screening suicidality for the film 'Night, Mother. Lines show the regression model for three illustrative values of identification (low, medium and high). For centred baseline suicidality and identification, scores of 0 represent the arithmetic mean. The identification scores were divided into three equally sized intervals (low, medium and high) and the model was evaluated at the interval c points. 
lower suicidality scores but did not change in the group with higher suicidality scores. A possible explanation for this finding can be found in Festinger's social comparison theory, ${ }^{32}$ which suggests that people tend to evaluate themselves by comparing themselves with other individuals. The confrontation with the hopeless situation portrayed in the suicide film ('Night, Mother) may have produced some type of 'contrast effect' ${ }^{28}$ that led to a more positive self-evaluation in the group without any signs of suicidality. This conclusion is consistent with the findings of Mares \& Cantor, ${ }^{33}$ who suggested that people use sad movies to cope with negative life experiences. Viewers with low suicidality seem to be capable of reaching a positive conclusion about their own lives when exposed to the tragic outcome of the protagonist.

\section{The impact of $A$ Single Man (film ending with the protagonist's death by natural causes)}

Notably, a significant deterioration of viewers' mood and an increase in depression were also recorded in individuals who watched the film where the protagonist died from natural causes (heart attack) (A Single Man). The fact that this film ends with the main character's natural death likely accounts for the negative emotional reactions in this group, which is concordant with affective disposition theory. ${ }^{27}$ Importantly, there was no film-induced change in suicidality among viewers with lower or higher baseline suicidality, which suggests that more suicidal individuals are not negatively affected by portrayals of natural death.

\section{The impact of Elizabethtown (film concluding with a happy ending)}

Viewers of the film Elizabethtown, which ends happily, did not experience any negative film effects, but reported an increase in life satisfaction and assumed benevolence of the world. These effects may be due to the kind and benevolent portrayal of the world that frames the protagonist's coping with his personal crisis in this film. While these findings suggest a possible beneficial short-term effect of a media portrayal of successful coping in adverse circumstances, Elizabethtown did not seem to affect the most important outcome variable, namely, suicidality. Based on the present findings, we can conclude that the media portrayal of successful coping when facing adverse circumstances increases life satisfaction, which is an important suicide-protective factor, and this increase is particularly pronounced among more vulnerable individuals.

\section{Limitations}

Clinically suicidal individuals with a suicidality score $\geqslant 106^{23}$ were excluded from participation in our study for ethical reasons, and the generalisability of the results beyond individuals with moderate depression or suicidality scores to this high-risk group remains unclear. Suicidal individuals may be particularly prone to increases in suicidal ideation after exposure to media content culminating in a suicide. ${ }^{11,12}$ Of note, suicidality has often been described within a 'continuous model', which implies that a core difference between low and high suicidality is increased internal pressure towards suicidal action. ${ }^{34}$ A further study limitation is that the films used in this analysis, while similar in terms of genre and portrayal of on-screen violence, differed with regard to many other characteristics beyond the portrayal of suicidality, such as sound, light and characters portrayed. Factors such as audio and visual stimuli, ${ }^{35,36}$ as well as camera positions, ${ }^{26}$ have an impact on identification with the protagonist and affective responses. ${ }^{7}$ Thus, differences across film groups may be based on factors other than the portrayal of suicidality. However, the stylistic elements of a film, such as the soundtrack, usually support the content of a film, ${ }^{35}$ particularly in mainstream movies as used in the present study. A further limitation is that our sample was not representative of the general public. Young female student populations were overrepresented in the study sample. Previous research suggested that the suggestive effects of suicide portrayals may be most relevant to young individuals. ${ }^{37}$ However, more research is necessary to evaluate these effects in different sociodemographic groups. Finally, group sizes were relatively small, resulting in limited statistical power. We therefore cannot rule out the presence of unidentified associations in the subgroup analyses.

\section{Implications for practice, policy and research}

The finding that suicidal ideation increased among viewers of 'Night, Mother, who experienced comparatively higher suicidality, is of great relevance to suicide research and prevention as it highlights the need to exert great caution when suicidal individuals are shown a film that culminates with the protagonist's suicide. The finding also highlights that any suicide awareness material featuring a completed suicide needs to be tested for vulnerable individuals as individuals with some degree of baseline suicidality seem to react in a different way to the portrayal of a suicide compared with psychologically stable individuals. Media guidelines for reporting on suicides, which are currently primarily aimed towards text-based media, ${ }^{38}$ need to be adapted for suicide portrayals in films and television programmes, and guidance on the portrayal of suicidality should be included in guidelines for the development of mental health awareness campaigns. ${ }^{39}$

Importantly, the impact of suicide-related film content seems not only to differ with regard to the viewers' vulnerability to suicide and their identification with the suicidal character, but also with regard to how the suicidal crisis is portrayed. Consistent with several ecological studies on the potential impact of news reports on suicide, ${ }^{11,40}$ this study highlights that not every suicide-related media portrayal results in an increase of suicidal tendencies in the audience. The portrayal of the successful mastering of a crisis in particular may have some positive impact on the audience, and further research using individual data is necessary to determine the media characteristics that enhance the protective effects of suiciderelated media portrayals in accordance with the Papageno effect. ${ }^{14}$

The present study provides a rich basis for further research in this topic. Future studies using larger sample sizes are necessary to investigate pathways between baseline vulnerability, identification and film effects, and to investigate differences with regard to gender and age groups. Particularly, research on the impact of suicide portrayals on individuals at risk is needed, provided that these studies are conducted under close supervision in accordance with ethical considerations. Studies with a longer follow-up to investigate possible long-term effects of media portrayals seem warranted. Films that are identical with regard to characteristics other than the outcome of the crisis being portrayed are needed to disentangle specific characteristics that may alter the effects of the stimulus material. Further, the impact of suicide portrayals may vary with characteristics such as film genre (e.g. horror films $v$. dramas), or with the protagonist's social status (e.g. portrayal as a hero $v$. villain), ${ }^{9,15}$ and the impact of these characteristics on film effects requires further scrutiny.

Benedikt Till, DSc, Markus Strauss, BSC, Suicide Research Unit, Institute of Social Medicine, Center for Public Health, Medical University of Vienna, Austria; Gernot Sonneck, MD, Crisis Intervention Center and Ludwig Boltzmann Institute for Social Sonneck, MD, Crisis Intervention Center and Ludwig Boltzmann Institute for Social
Psychiatry, Vienna, Austria; Thomas Niederkrotenthaler, MD, PhD, MMSc, Suicide Research Unit, Institute of Social Medicine, Center for Public Health, Medical University of Vienna, Austria

Correspondence: Benedikt Till, Suicide Research Unit, Institute of Social Medicine, Center for Public Health, Medical University of Vienna, Kinderspitalgasse 15, 1090 Vienna, Austria. Email: benedikt.till@meduniwien.ac.at

First received 13 Jun 2014, final revision 30 Oct 2014, accepted 3 Nov 2014 


\section{References}

1 Pirkis J, Blood RW. Suicide and the media. Part I: Reportage in nonfictional media. Crisis 2001; 22: 146-54.

2 Sisask M, Värnik A. Media roles in suicide prevention: a systematic review. Int J Environ Res Public Health 2012; 9: 123-38.

3 Niederkrotenthaler T, Fu KW, Yip PS, Fong DY, Stack S, Cheng Q, et al. Changes in suicide rates following media reports on celebrity suicide: a meta-analysis. J Epidemiol Community Health 2012; 66: 1037-42.

4 Martin G. Media influence to suicide: the search for solutions. Arch suicide Res 1998; 4: 51-66.

5 Pirkis J, Blood RW. Suicide and the media. Part II: Portrayal in fictional media. Crisis 2001; 22: 155-62.

6 Stack S. Copycat effects of fictional suicide: a meta analysis. In Suicide and the Creative Arts (eds S Stack, D Lester): 231-44. Nova Science, 2009

7 Huesmann LR, Taylor LD. The role of media violence in violent behavior. Annu Rev Public Health 2006; 27: 393-415.

8 Fu KW, Yip PS. Estimating the risk for suicide following the suicide deaths of 3 Asian entertainment celebrities: a meta-analytic approach. J Clin Psychiatry 2009; 70: 869-78.

9 Niederkrotenthaler T, Till B, Kapusta ND, Voracek M, Dervic K, Sonneck G. Copycat effects after media reports on suicide: a population-based ecologic study. Soc Sci Med 2009; 69: 1085-90.

10 Till B, Vitouch P, Herberth A, Sonneck G, Niederkrotenthaler T. Personal suicidality in the reception of and identification with suicidal film characters. Death Stud 2013; 37: 383-92.

11 Cheng AT, Hawton $\mathrm{K}$, Chen TH, Yen AM, Chen CY, Chen LC, et al. The influence of media coverage of a celebrity suicide on subsequent suicide attempts. J Clin Psychiatry 2007; 68: 862-6.

12 Zahl DL, Hawton K. Media influences on suicidal behaviour: an interview study of young people. Behav Cogn Psychoth 2004; 32: 189-98.

13 Stack S, Kral M, Borowski T. Exposure to suicide movies and suicide attempts. Sociol Focus 2014; 47: 61-70.

14 Niederkrotenthaler T, Voracek M, Herberth A, Till B, Strauss M, Etzersdorfer E, et al. Role of media reports in completed and prevented suicide: Werther $v$. Papageno effects. Br J Psychiatry 2010; 197: 234-43.

15 Stack S, Bowman B. Suicide Movies: Social Patterns 1900-2009. Hogrefe 2012.

16 National Action Alliance for Suicide Prevention, Research Prioritization Task Force. A Prioritized Research Agenda for Suicide Prevention: An Action Plan to Save Lives. National Institute of Mental Health and the Research Prioritization Task Force, 2014.

17 World Health Organization. The World Health Report 2001. Mental Health New Understanding, New Hope. WHO, 2001.

18 Becker P. Skalen für Verlaufsstudien der emotionalen Befindlichkeit [Scales for longitudinal studies of affective state]. Z Exp Angew Psychol 1988; 35 : 345-69.

19 Amado-Boccara I, Donnet D, Olié JP. La notion d'humeur en psychologie [The concept of mood in psychologyl. Encephale 1993; 19: 117-22.

20 Lehrl S, Gallwitz A. Erlanger Depressions-Skala: EDS [Erlangen Depression Scale: EDS]. Vless, 1983

21 Diener E, Emmons RA, Larsen RJ, Griffin S. The satisfaction with life scale. J Pers Assess 1985; 49: 71-5.
22 Janoff-Bulman R. Assumptive worlds and the stress of traumatic events: applications of the schema construct. Soc Cognition 1989; 7: 113-36.

23 Linehan MM, Goodstein JL, Nielsen SL, Chiles JA. Reasons for staying alive when you are thinking of killing yourself: the reasons for living inventory. J Consult Clin Psychol 1983; 51: 276-86.

24 Range LM. The family of instruments that assess suicide risk. J Psychopathol Behav Assessment 2005; 27: 133-40.

25 Perlmuter LC, Noblin CD, Hakami M. Reactive effects of tests for depression: theoretical and methodological considerations. J Soc Clin Psychol 1983; 1: 128-39.

26 Cohen J. Defining identification: a theoretical look at the identification of audiences with media characters. Mass Commun Soc 2001; 4: 245-64.

27 Zillmann D. The psychology of suspense in dramatic exposition. In Suspense: Conceptualizations, Theoretical Analyses, and Empirical Explorations (eds P Vorderer, HJ Wulff, M Friedrichsen): 199-231. Routledge, 1996.

28 Till B, Niederkrotenthaler T, Herberth A, Vitouch P, Sonneck G. Suicide in films: the impact of suicide portrayals on non-suicidal viewers' well-being and the effectiveness of censorship. Suicide Life Threat Behav 2010; 40: $319-27$

29 Till B, Niederkrotenthaler T, Herberth A, Voracek M, Sonneck G, Vitouch P. Coping and film reception: a study on the impact of film dramas and the mediating effects of emotional modes of film reception and coping strategies. J Media Psychol 2011; 23: 149-60.

30 Ringel E. Der Selbstmord: Abschluss einer krankhaften psychischen Entwicklung. Eine Untersuchung an 745 geretteten Selbstmördern [Suicide: conclusion of a psycho-pathological development. A study on 745 rescued suicides]. Klotz Verlag, 1997.

31 Shneidman ES. Suicide as Psychache: A Clinical Approach to Self-Destructive Behavior. Jason Aronson, 1995.

32 Festinger L. A theory of social comparison processes. Hum Relat 1954; 7: $117-40$.

33 Mares M-L, Cantor J. Elderly viewers' responses to televised portrayals of old age. Empathy and mood management versus social comparison. Commun Res 1992; 19: 459-78.

34 Wolfersdorf M, Mauerer C, Franke C, Schiller M, König F. Krisenintervention bei Suizidalität im ambulanten und stationären psychiatrisch-psychotherapeutischen Bereich [Crisis intervention in psychiatric and psychotherapeutic in- and outpatient settings]. Psychother 1999; 4: 146-54.

35 Boltz MG. Musical soundtracks as a schematic influence on the cognitive processing of filmed events. Music Percept 2001; 18: 427-54.

36 Roy M, Mailhot JP, Gosselin N, Paquette S, Peretz I. Modulation of the startle reflex by pleasant and unpleasant music. Int J Psychophysiol 2009; 71: $37-42$.

37 Schmidtke A, Schaller, S. The role of mass media in suicide prevention. In The International Handbook of Suicide and Attempted Suicide (eds K Hawton, K van Heeringen): 675-97. Wiley-Blackwell, 2000.

38 World Health Organization. Preventing Suicide. A Resource for Media Professionals. WHO, 2008.

39 Substance Abuse and Mental Health Services Administration. Developing a Stigma Reduction Initiative. Center for Mental Health Services, Substance Abuse and Mental Health Services Administration, 2006.

40 Pirkis JE, Burgess PM, Francis C, Blood RW, Jolley DJ. The relationship between media reporting of suicide and actual suicide in Australia. SOC Sci Med 2006; 62: 2874-86. 